\title{
Hacia un estado de la cuestión de las investigaciones sobre desinformación / misinformación
}

Recibido: 31 de agosto de 2012

Aceptado: 29 de abril de 2013

Publicado: 29 de noviembre de 2013
Luis Romero Rodríguez

1rr840@alboran.ual.es

Universidad de San Martín de Porres

(Perú)

Resumen: El concepto de desinformación tiene casi tantos significados como la cantidad de autores que lo han tratado. Desde la perspectiva semiótica y psicológica, la desinformación pareciera ser el resultado de la falta de adecuación de lo que se comunica con la realidad actual de un objeto. El enfoque de las Ciencias Políticas y de las Relaciones Públicas toma la desinformación como una aplicación de técnicas de manipulación de las masas y la opinión pública, mientras que la visión de las Ciencias de la Comunicación y de la Información la considera una característica natural de los medios de comunicación y de un ecosistema comunicativo claramente sobresaturado. En este trabajo se exponen las distintas afirmaciones que, desde el seno de todas las ciencias referidas, se le ha dado al asunto de la desinformación.

Palabras clave: Desinformación, manipulación informativa, opinión pública, comunicación social, periodismo, comunicación masiva.

Abstract: The concepts of disinformation and misinformation have almost as many meanings as the number of authors who have treated them. Considered from the semiotic and psychological point of view, disinformation and misinformation seem to be the result of the inadequacy of what is communicated to the reality of an object. The focus of both Political Science and Public Relations is set on disinformation / misinformation as an example of how masses and public opinion can be manipulated, while the vision of Communication Sciences and Information considers such behaviours as natural features of the media in a clearly oversaturated communications ecosystem. This paper describes the different approaches to the topic of disinformation/misinformation made in the above mentioned scientific disciplines.

Key words: Disinformation / Misinformation, Manipulation, Public Opinion, Social Communications, Journalism, Mass Communication. 


\section{Introducción}

El presente trabajo plantea una aproximación crítica a los estudios sobre la desinformación desde una perspectiva pragmalingüística y a las diferentes definiciones, enumeraciones y clasificaciones de las estratagemas de desinformación. De esta manera, se podrá contar con un claro punto de partida para futuras investigaciones sobre una cuestión tan patentemente sentida en nuestros tiempos.

Aunque el término desinformación es relativamente reciente, hay referencias del uso de esta técnica ya en los tiempos antiguos de nuestra cultura. En cuanto al vocablo mismo, no se atestigua hasta 1949, aunque ya se apunta en diversas teorías de la comunicación y la propaganda, sobre todo a partir de los años 20, con la escuela funcionalista de Lasswell (1971), los avances de las Relaciones Públicas en la obra de Bernays (1928) y la aplicación de técnicas de "propaganda negra" de Joseph Göebbels (ápud Doob, 1950).

El Diccionario de la Real Academia Española (2001) define el término "desinformación" como "acción y efecto de desinformar" y, en la segunda acepción, como "falta de información, ignorancia". Sin embargo, las cosas se complican cuando de delimitaciones científicas se trata. Uno de los grandes debates que se han suscitado acerca de la ontología de la desinformación parte de las investigaciones de Floridi (1996, 2005 y 2011) y Fallis (2009 y 2011) que analizan la desinformación como un producto que pudiere ser, convertirse en o provenir de una acción informativa, tanto semántica como gráfica.

Para Floridi (2011: 80), la veracidad es elemento existencial sine qua non para que un mensaje sea informativo. Por este motivo, no considera que la desinformación sea una variedad de la información, postura compartida por Dretske (1981: 45-46), Grice (1989: 371), Frické (1997: 887-890) y Fallis (2011: 201-214 y 2009: 3-7). Los citados autores consideran que un acto comunicativo, independientemente de la voluntad del emisor, podría convertirse en desinformativo si contiene la intención de engañar, si los datos son falsos y si el receptor considera que se trata de un contenido verdadero, razonable y lógico. Esto lleva incluso a postular que la desinformación es un subproducto informativo.

Esta discusión, lejos de ser baladí, contiene un primer problema que los esfuerzos teóricos multidisciplinarios (tanto de lingüistas como de comunicadores, psicólogos, sociólogos y filósofos de la información de escuelas norteamericanas, alemanas, francesas y españolas) han intentado dilucidar en diversos trabajos de investigación: aunque se mantienen ciertos conocimientos empíricos sobre el tema, no se ha logrado unificar la propia esencia de la palabra, su contexto, su pragmalingüística y aplicaciones a través de los conceptos que cada ciencia trae a escena.

Como han puesto de manifiesto López (2004) y Romero (2012a y 2012b), el concepto actual de desinformación prefiere no usar el prefijo "des-" como relación inversa a la acción que la precede o en relación negativa con el verbo "informar". Antes bien, se busca establecer una correlación estructural: el actual ecosistema comunicativo, globalizado, hipertextual, saturado y socializado (a la vez en interacción con la propia metamorfosis y mediamorfosis 
del modelo del periodismo y el ecosistema comunicativo que busca subsistir) hace que sea imposible informarse sin, a la vez, quedar desinformado.

Por tal razón, al estar ubicados en un espacio-tiempo de morfogénesis y de mediamorfosis, son los conceptos los que deben cambiar en relación a la práctica y no al contrario. Todo contenido informativo viene a la vez en su propio seno, con una carga de desinformación, de interrelación de tecnología, comunicación y sociedad. Se convierte al usuario/autor a la vez en usuario/difusor, usuario/receptor. Se multiplican los espectros de las propias (des)informaciones de los medios tradicionales, sumado a las diversas y heterogéneas interpretaciones y lecturas transversales que cada cual le da a una "información", que impactan evidentemente en la exégesis colectiva, es decir, en la capacidad social de reinterpretar una información de manera crítica y objetiva.

Esta situación, con exigencias mayores equitativas a la amplitud del nuevo "círculo social" (combinada con las mismas necesidades propias del individuo, su contexto dinamizador y su nivel de actividades) generan en él una sobresaturación de informaciones, caldo de cultivo propicio no sólo para estar desinformado de todos los espectros de la realidad para la toma de decisiones (Romero, 2012a y 2012b), sino impregnado de su propia identidad y con sentido acrítico sobre su entorno (Gergen, 1992) llegando incluso a la indefensión ciudadana y al aislamiento cognitivo (López, 2004).

Ya acercándonos a la idea que todo acto informativo contiene en sí su propia acción desinformativa, Karlova (ápud Karlova y Lee, 2011) entra en la discusión analizando el caso contrario, esto es, si un acto desinformativo puede a la vez ser informativo. Aunque ya antes hicieron algo así Fox (1983), Buckland (1991) y Fallis (2009: 3-7), Karlova establece que la objetividad existe independientemente de la visión subjetiva de los emisores o fuentes de información, por lo que la desinformación, al no ser el traslado objetivo de la realidad (como tampoco lo es enteramente la información) puede ser informativa siempre y cuando las situaciones de cambios objetivos en el sujeto o la acción sobre la que se intenta hacer referencia, cambie y se convierta en una realidad objetiva.

\section{Objeto de la investigación}

Se busca en este artículo realizar una revisión exhaustiva de los diferentes textos y publicaciones que han tratado la desinformación desde las ciencias sociales. El objetivo es precisar los antecedentes del estudio científico de la materia y señalar áreas en las que no se hayan encontrado desarrollos exhaustivos.

El interés surge por la posible demanda de la sociedad en conocer el grado de penetración que tiene el fenómeno de la desinformación en nuestro acontecer diario. No podemos sustraernos al hecho de que vivimos en un momento histórico caracterizado por una interacción comunicativa más compleja, un ecosistema comunicacional saturado, un auge en el uso de las redes sociales y, en fin, cierta crisis informativa y de los medios de comunicación que podrían ser caldo de cultivo para un incremento de la presencia de desinformación en nuestro hábito de consumo cotidiano. 


\section{Metodología}

Se adoptará una visión historiográfica de los estudios de la desinformación, sin descuidar otros que, por ser previos a la formalización de su definición operativa, manifiesten posturas acerca de la manipulación social, la tergiversación informativa y las estrategias discursivas del engaño. Esta perspectiva se completará con investigaciones que desde las ciencias sociales hayan tratado el tema en cuestión.

Hay que advertir que las conclusiones de las ciencias sociales, lejos de resultar infalibles y exactas, no pueden considerarse un marco de resultados estrictos y fieles, por lo que este análisis de fuentes documentales no se centrará en la búsqueda de errores materiales ni en la crítica de los diversos autores contemplados. Antes bien, escudriñará en las diversas obras para ubicar un subárea del estudio de la desinformación que puede no haber sido tratada con la amplitud suficiente, verbigracia, en el análisis pragmático de las estrategias de desinformación y en su clasificación.

Rizo (2009: 16) ha referido que el común sentir de la perspectiva académica asume que la comunicación es un objeto de estudio de sus propias teorías, las cuales han generado algunas aristas que componen el propio proceso comunicativo. En este sentido, la comunicación se nutre y toma por propias explicaciones y aproximaciones de sus fenómenos desde ciencias como la física, la semiótica, la sociología, la psicología, la política y la economía. Así, se entiende que algunas corrientes de estudio confieren a la comunicación un carácter de ciencia impropia e indemostrable. No obstante, conviene indicar que la indemostrabilidad no implica necesariamente la inexistencia.

Cualquier teoría que se aprecie en cualquier campo de conocimiento, sobre todo en las ciencias sociales, será insuficiente para explicar sus propios fenómenos íntegramente, por lo que ese carácter ficcional de la comunicación (que no permite alcanzar una realidad objetiva) no debe verse como una negación de su propio carácter científico, sino como muestra de su carácter eminentemente social, que ubica su objeto de estudio en la dinámica concurrente y en los cambios continuos de las interacciones y las construcciones teóricas y pragmáticas.

De esta manera, es la Comunicación la piedra angular epistemológica del presente estudio, un estado de la cuestión y marco referencial idóneo para identificar oportunidades de investigación acerca de la desinformación que no hayan sido tratadas con suficiente profundidad. Con la pertinencia, suficiencia y objetividad de la fuente como criterios prioritarios de la selección de material, el trabajo será de deducción apoyada en la localización, catalogación y revisión documental.

La posición epistemológica asumida en el desarrollo del presente artículo está vinculada a un paradigma explicativo-cualitativo que busca ejercer una labor de aproximación teórica de un fenómeno semiótico, comunicativo y social incrementado con el actual ecosistema comunicativo. La selección del corpus y la recogida de datos se ajustará a la suficiencia y pertinencia de la fuente informativa y será catalogada la perspectiva historiográfica por el abordaje Whig, ofreciendo una mirada anacrónica sobre el pasado en permanente referencia al presente y su contenido teórico (Butterfield, 1931). 


\section{Hipótesis}

La hipótesis de partida de la presente investigación es la necesidad científica de hacer una lectura crítica al discurso como mensaje descendente desde el podio del poder (académico, político, económico o mediático) hacia la sociedad. Los estudios de desinformación, si bien han sido tratados desde la perspectiva de su filosofía, ontología, epistemología y crítica, no han tenido mayor desarrollo científico en precisar las estrategias pragmalingüísticas más comunes en el campo. Esto quiere decir que el interés académico se ha centrado en darle un concepto válido a la luz de diversas escuelas de pensamientos y disciplinas, mientras que se ha podido dejar de lado el análisis y la tipificación de las estratagemas de desinformación más comunes.

\section{Una visión historiográfica sobre la desinformación}

La palabra desinformación y su primigénesis conceptual parecen provenir de la inclusión del término Dezinformatsia (дезинформация) en la primera edición (1949) del Diccionario de la Lengua Rusa (Словарь русского языка) definida esta como la "acción de inducir a confusión a la opinión pública mediante el uso de informaciones falsas". Sin embargo, aunque el uso del término es de reciente data, la práctica común de lo que la define es mucho más antigua. Así puede verse, no ya sólo en la propia historia universal, las literaturas clásicas o los milenarios textos chinos, sino también en la obra de Lenin ¿Qué hacer? (1902), en la que proclama la importancia de la propaganda, la agitación y el engaño como elementos integrales de la estrategia comunista. Ya para 1972, el término desinformación había sido incluido en la Enciclopedia Soviética, para referirse a noticias falsas, engañosas y deformadas. En el Petit Larousse de 1982, se le añadió a la definición los conceptos de la omisión, el silencio y la censura (Rivas, 2005).

En una obra tan antigua como la Odisea, atribuida al poeta Homero y quizás escrita en el siglo VIII a. C., se menciona en los cantos VIII y XI, la historia de un caballo gigante de pulimentada madera, construido por Epeo con ayuda de Atenea. Oculto en su interior, un grupo especial de guerreros a las órdenes de Odiseo esperaba su momento. Cuenta Virgilio en la Eneida cómo los troyanos deciden introducir el caballo en la ciudad después de prestar oídos a las mentiras de Sinón (Verg., Aen. II, 69 ss.) y de comprobar los portentos que acontecen a Laocoonte (Verg., Aen. II, 199-227), el sacerdote que se había dado cuenta del engaño y había intentado denunciarlo (Verg., Aen. II, 42-49; Pabón, 2006: 29-33). Es una referencia literaria de las tácticas militares de desinformación y engaño.

El diálogo Politeia (La República), de Platón, ya hablaba de la mentira piadosa como base fundamental de las estructuras del poder del Estado. Apunta que los gobernantes nacían con oro en las venas y destinados a gobernar, pero también algunos campesinos y obreros estarían predestinados a ascender. Aunque revista forma de mito, o quizá por eso mismo, se formula como una mentira noble que obliga a los súbditos a aceptar una superioridad natural de la élite gobernante al tiempo que fomenta que esta se crea mejor que los súbditos. Nos encontramos, pues, con engaño revestido de relato moral (García: 2004). 
Aunque de más reciente recepción en nuestra cultura, El arte de la guerra, tratado seguramente redactado entre los siglos VI y IV a. C. y atribuido a Sunzi (Sun Tzu), podemos leer que: "el principal engaño que se valora en las operaciones militares no se dirige sólo a los enemigos, sino que empieza por las propias tropas, para hacer que le sigan a uno sin saber adónde van" (ápud Ramírez, 2006: 33-34).

El controvertido capítulo XVIII de El príncipe, de Nicolás Maquiavelo (1532), recomienda al príncipe mostrarse de acuerdo con los valores que desprecia (sobre todo con la paz y la fe). Así, se adapta a las exigencias del vulgo, cuya ignorancia y simpleza en cierto modo justifica que se le engañe (ápud Catalán, 2009: 15). En ese mismo capítulo se lee: "Los hombres son tan simples y de tal manera obedecen a las necesidades del momento que quien engaña encontrará siempre quien se deje engañar" (ápud García, 2004: 92). Posiblemente, es una manera de señalar la importancia de la manipulación y el engaño en la propia razón de Estado, lo que nos acerca a un sentido moderno de la desinformación.

En 1534, el reformador radical germano Sebastian Franck publicó en sus Paradoxa el aforismo Mundus vult decipi ("El mundo quiere ser engañado"). La formulación va a aparecer amplificada por Carlo Caraffa, cardenal de Nápoles: Populus vult decipi, ergo decipiatur ("El pueblo quiere ser engañado, luego engáñesele"), según cuenta Catalán (2009: 13). Aunque no es aplicable a la desinformación política, no podemos por menos que recordar la presencia de esta imagen del vulgo maleable y engañable en El arte nuevo de hacer comedias, con su famosa formulación:

"y, cuando he de escribir una comedia, encierro los preceptos con seis llaves; saco a Terencio y Plauto de mi estudio, para que no me den voces (que suele dar gritos la verdad en libros mudos), y escribo por el arte que inventaron los que el vulgar aplauso pretendieron, porque, como las paga el vulgo, es justo hablarle en necio para darle gusto".

Son contextos en los que bien podemos rastrear el uso de técnicas de engaño desde las élites gobernantes y culturales de esta época.

En pleno apogeo de la Ilustración, el músico y literato alemán Christian Schubart escribió la canción Die Forelle ("La trucha") mientras estaba preso en la fortaleza de Asperg en 1775 por una polémica revista en contra del régimen político y del estamento eclesiástico. Puede entenderse como una crítica al manejo informativo de la época, disfrazado en las metáforas, parábolas y recursos literarios. Citamos el texto traducido:

"Mientras el agua siga clara y no se enturbie, pensé, 
no podrá coger a la trucha

con su anzuelo.

Finalmente, el ladrón

se cansó de esperar.

Pérfidamente enturbió el arroyuelo

$\mathrm{y}$, antes de que pudiera darme cuenta,

la caña dio una sacudida

y el pececillo quedó atrapado.

Yo con la sangre alterada,

vi la presa engañada".

El texto nos ofrece un buen ejemplo del vital interés que las élites del poder de los tiempos de la Ilustración depositaban en la desinformación y el engaño, si tenemos en cuenta que el autor fue preso por sus escritos críticos contra el absolutismo alemán y por la denuncia que hizo del declive del ducado de Württemberg. Expone metafóricamente que, si el contexto de la información es transparente, es imposible lograr que por sí misma logre su función desinformativa, mientras que ocurre lo contrario cuando el entorno de comunicativo no deja ni atisbar sus fines.

La disertación titulada ¿Es útil para los hombres ser engañados? (Marqués de Condorcet, 1790) se opone con rotundidad a la llamada "mentira noble", esto es, el derecho del gobernante a mentir al pueblo en bien de este (ápud Catalán, 2009: 12). Se contrapone, así, a mentalidades como las que advertíamos en los textos antes revisados de Platón o de Maquiavelo. Si nos fijamos en su contemporáneo Johann Wolfgang von Goethe, contraria visión nos ofrece el epigramático Lug Oder Trug ("Mentira o engaño") contenido en sus Römische Elegien (1795). Ahí se nos señala que la acción del engaño de las élites discursivas era un mal menor e incluso necesario:

“¿Debe engañarse al pueblo?

Desde luego que no.

Mas si le echas mentiras, mientras más gordas fueren, resultarán mejor".

Incluso hasta inicios del siglo XX, los gobiernos y las élites del poder no necesitaban sumirse en grandes tácticas de desinformación. La propaganda y el uso de mentiras eran más simples porque, generalmente, el flujo comunicativo era directo de élites a súbditos. De hecho, antes del período de revoluciones en Francia y América, el analfabetismo era la regla, y el control de las obras literarias y académicas (a través de la censura y la quema de libros) era habitual. Combinado esto con la represión a la que se sometía a quienes divulgaban cierto nivel de conocimientos más allá del convencional (teológicos, metafísicos o científicos) bien podemos ver que las élites mantenían la información para sí mismos y retiraban los remanentes de la palestra pública (DPProgram, 2010). 
De hecho, hasta la Revolución francesa, los regímenes se caracterizaban por una ausencia total de libertades individuales, por lo que los gobernantes no necesitaban informar a los súbditos (no considerados ciudadanos) acerca de la acción de gobierno, mientras que la modernidad se comienza a definir por el desarrollo de las tecnologías de la información a la vez de la instauración de las democracias en el mundo occidental, por lo que es a mediados del siglo XIX cuando oficialmente comienza a gestarse la prensa escrita, aún cuando la imprenta se había inventado 400 años antes.

Luego de las revoluciones y en el nacimiento de la era industrial, la multiplicidad de imprentas y la paulatina reducción del analfabetismo comenzaron a crear una batalla política en la celulosa impresa. La titularidad de un medio de comunicación daba a un partido o a una persona poder político y económico suficiente para controlar cierta parte de la población. Con la llegada de la radiodifusión (1920), el analfabetismo ya no era una limitante para estar (des)informados, mientras que la presencia de los medios se hacía más común en cada rincón de nuestro planeta (Moragas, 1985).

En 1923, Edward Bernays, teórico y pionero de las Relaciones Públicas y del $\operatorname{spin}^{1}$ (ápud Stauber y Rampton, 2001:27), relató en Crystallizing Public Opinion que la opinión pública es moldeable y manipulable siempre que el producto o concepto le parezca atractivo a la audiencia. En otro de sus trabajos, Propaganda, comparaba la opinión pública como un "rebaño que necesita ser guiado porque es susceptible de acoger liderazgos", con el fin de "controlar a las masas sin que estas lo sepan" (Bernays, 1928: 4). El mencionado autor comprendía que quienes manipulan el mecanismo oculto de la sociedad constituyen un gobierno invisible, un verdadero poder: "Somos gobernados, nuestras mentes moldeadas, nuestros gustos formados, nuestras ideas sugeridas mayoritariamente por hombres de los que nunca hemos oído hablar [...] son ellos los que manejan los hilos que controlan la opinión pública" (ibídem: 4-7).

De 1933 a 1945, Joseph Goebbels fue Ministro de Propaganda e Información del régimen nazi. A su cargo tenía el control absoluto de todos los medios de comunicación, en los cuales no sólo era evidente la exaltación personalista de Hitler, sino ciertas estrategias para la censura y el control de la información, revisadas con detenimiento por Leonard W. Doob en su “Goebbels' Principles of Propaganda" (1950). En ese artículo, se analiza la mecánica de diecinueve principios de propaganda y de desinformación, tipificando las directrices de las acciones persuasivas y disuasivas del régimen nazi hacia la opinión pública.

1 Término anglosajón que no tiene traducción actual al castellano y que refiere a un conjunto de técnicas de propaganda en las cuales se presenta una interpretación distinta a un hecho a favor o en contra de una determinada organización o figura pública (Roberts, 2005). La técnica del spin si bien tiene una lectura real de un acontecimiento, usualmente se maneja con tácticas de manipulación de comportamiento de la opinión pública, presentando dichos hechos de manera creativa o con un giro de lectura diferente. 
La Escuela marxista de Frankfurt, en especial Herbert Marcuse (1964: 284) con El hombre unidimensional, advierte que los medios generan una alienación del hombre hacia el consumo y utilizan el poder para afianzar su statu quo con el fin de desviar la atención de los ciudadanos de las preocupaciones que verdaderamente afectan sus vidas (ibidem: 101). Más adelante, en la tercera generación de la misma escuela, Habermas (1981) no considera a los medios de comunicación como una extensión del poder, ya que la instancia periodística acude a él como ente externo, atravesando todo proceso comunicativo por una lógica de incompletitud y de dislocación semiótica, por lo que la independencia de los medios es más una circunstancia de lógica por el mismo contexto de la reinterpretación de los significados por parte de los receptores, actuando como racionalidad colectiva o pragmática trascendental y no como multiplicidad de sujetos e interpretaciones.

De esto se colige que los medios, lejos de actuar como una subforma del poder, proceden en tercera persona, es decir, como un sujeto ajeno a este que a la vez es fragmentario si no toma al primero en consideración, y que se debe entender al poder y a los medios como dos entes que se complementan pero que ninguno está subrogado al otro, incluida la propia capacidad de reinterpretación de los códigos por cada uno de los receptores que conforman la audiencia.

Desde 1969, Herbert I. Schiller venía analizando las estrategias utilizadas por los mass media para manipular la opinión pública. Haremos especial referencia a sus Mass Communications and American Empire (1969) y Mind Managers (1973). En estos trabajos, hace referencia a lo que considera tres mitos institucionales: la propiedad privada, la neutralidad y el pluralismo de los medios de comunicación, uniendo estas reflexiones con la ausencia de análisis de los conflictos sociales y el incremento de emociones humanas que demandan cierto tipo de información. Se sustituyen, así, contenidos de importancia social por banalidades que, al final, responden al propio clamor popular de entretenimiento (Schiller, 1969 y 1987). En esta perspectiva, se comienza a considerar que la sobresaturación informativa puede generar una escotomización social y, por ende, una anomia frente a las actitudes y acontecimientos que pueden afectar nuestras vidas.

En Occidente, el término desinformación fue incluido oficialmente en un informe gubernamental por primera vez en el Special Report No. 88 de la Oficina de Asuntos Públicos del Departamento de Estado de los Estados Unidos de Norteamérica (1981), titulado Forgery, Disinformation, Political Operations, en el cual se lee que existían "medidas activas del bloque soviético para desacreditar y debilitar la imagen de Estados Unidos y otras naciones", entre las cuales se enumera la propia desinformación ${ }^{2}$.

2 En agosto de 1986, el Departamento de Estado de Estados Unidos emite otro documento denominado A Report on Substance and Process of Anti-US Disinformation and Propaganda Campaigns, en cuyas conclusiones se expone que la "Unión Soviética y sus aliados mantienen esfuerzos de diplomacia pública que incluyen un persistente programa de desinformación y engaño para desacreditar la imagen de los Estados Unidos y evitar que sean cumplidos los objetivos de la política exterior estadounidense" (United States Department of State, 1986: iii). 


\subsection{Los debates contemporáneos sobre la filosofía de la desinformación}

Distintos autores le han intentado dar una demarcación epistemológica y filosófica al término desinformación. Debemos empezar advirtiendo que los investigadores estadounidenses y franceses han separado la desinformación culposa o por error (misinformation, mésinformation) de la que se presenta con premeditación y dolo (disinformation, désinformation), con lo que han delimitado dos campos de estudio distintos cuya diferencia se basa en la preterintencionalidad del agente desinformante.

Un primer grupo de académicos, entre los que figuran Shultz y Godson (1984), O'Brien (1989), Fallet (2001), Fraguas de Pablo (1985), Martínez (1987), Jacquard (1988), Stahl (2006), Gackowski (2006), Bednard y Welch (2008) y Saariluoma y Maksimainen (2012) consideran que la desinformación no es de ninguna manera un subproducto de la información y que la propia tergiversación informativa depende de la voluntariedad del emisor. La mayoría de estas obras realizan estudios pormenorizados de las estrategias de engaño y tergiversación informativa del bloque soviético durante la Guerra Fría o parten de esos análisis para redefinir el asunto, por lo que es normal que se confunda en ellas el concepto de desinformación con el de contrainformación, ya que el uso consuetudinario y continuo de la palabra, así como la propia definición inicial de la misma, puede llevarnos a entender que desinformación es sinónimo de manipulación informativa, mientras que la tergiversación es voluntaria.

Guy Durandín (1995: 8) define la desinformación como un conjunto organizado de engaños en una era en que los medios de comunicación masivos se encuentran enormemente desarrollados. Para él, hay que analizar seis elementos: a) la diferencia entre conocimiento, realidad y discurso; b) la intención de engañar; c) los motivos que la causan; d) los objetos sobre los que recae; e) los destinatarios; y f) los métodos que utiliza.

Durandín parece ser el primer autor que dedica sus esfuerzos a clasificar las tres acciones primarias que pudieren considerarse desinformativas (y que comportan tanto acciones como omisiones) a saber: a) eliminar elementos o silenciar la totalidad de la información (omisión voluntaria o censura); b) alterar informaciones (manipulación informativa); y c) inventar acontecimientos.

Lingüistas como Teun Van Dijk (2006) o James F. Klumpp (1997) han dado un tratamiento exhaustivo a la ética del discurso en función de su legitimidad. El primero esgrime que la manipulación y la desinformación se entienden en términos de abuso de poder por las élites simbólicas que tienen acceso preferencial al discurso público (políticos, académicos, periodistas, entre otros) y manipulan el pensar colectivo en favor de sus propios intereses mediante una compleja triangulación de discurso, cognición y sociedad, para ejercer una influencia ilegítima sobre la opinión pública (Van Dijk, 2006: 49-74). Por su parte, Klumpp (1997: 119-121) refiere que el lenguaje se asume en la desinformación como una sombra de la realidad que se expresa, siendo el rol de la retórica manipular esa sombra para transmitir el resultado subyacente de lo que no puede ser directamente observado, interviniendo así en las subsecuentes acciones sociales. 
Un segundo grupo de autores, entre ellos Fox (1983), Loose (1997) o Karlova (Karlova y Lee 2011; Karlova y Fischer, 2012), consideran la desinformación como una especie de información que puede ser falsa, ambivalente, vaga o ambigua, pero que a la vez puede resultar informativa. De hecho, Fox (1983), uno de los pioneros contemporáneos en el estudio de la filosofía de la desinformación, sostiene que la información no necesita ser cierta para ser catalogada como tal.

Karlova y Lee (2011: 4) exponen en la siguiente tabla, que presentamos traducida, un resumen de las características de la información (misinformation) y la desinformación (disinformation):

Figura 1: Características de la información, la misinformation y la disinformation.

\begin{tabular}{|c|c|c|c|}
\hline & Información & Misinformation & Disinformation \\
\hline Verdadera & $\mathrm{S}$ & $\mathrm{S} / \mathrm{N}$ & $\mathrm{S} / \mathrm{N}$ \\
\hline Completa & $\mathrm{S} / \mathrm{N}$ & $\mathrm{S} / \mathrm{N}$ & $\mathrm{S} / \mathrm{N}$ \\
\hline Actual & $\mathrm{S}$ & $\mathrm{S} / \mathrm{N}$ & $\mathrm{S} / \mathrm{N}$ \\
\hline Informativa & $\mathrm{S}$ & $\mathrm{S}$ & $\mathrm{S}$ \\
\hline Engañosa & $\mathrm{N}$ & $\mathrm{N}$ & S \\
\hline
\end{tabular}

Fuente: Karlova y Lee (2011: 4).

Un tercer grupo de investigadores contemporáneos, entre ellos Isralson (1988), Rivas Troitiño (1989), Galdón López (1994) y Canevas (2006), exponen que la desinformación es un fenómeno que obtiene su relación de causalidad directamente del manejo periodístico de la información o del incumplimiento de normas éticas o lingüísticas en su ejercicio.

Refiere Rivas Troitiño (1989: 79) que el contenido desinformativo puede ser causado tanto por intencionalidad o error en la fuente como por silencio, por lo que el destinatario recibe, en consecuencia, un producto informativo incorrecto, incompleto o inexacto. Rivas clasifica el contenido desinformativo en:

- Para-información: Aquella proveniente de gabinetes de Relaciones Públicas y publicados como noticias.

- Pre-información: Aquella que no ha sido contrastada o confirmada.

- Intra-información: Producto del análisis de acontecimientos y otras informaciones.

- Sub-información: Que llega a la audiencia de forma incompleta o defectuosa.

- Súper-información o sobre-información: Exhaustiva o de opulencia comunicativa.

- Pseudo-información: Engañosa, irrelevante pero igualmente publicada.

- Contra-información: Que ataca frontalmente otra versión de un acontecimiento. 
Galdón López (1994) considera a la desinformación como un efecto causal-fenomenológico de la realidad del modelo de periodismo actual, con su idolatría de la actualidad y su lógica de incompletitud informativa, lo que lleva a la omisión de la información esencial y a la primacía de las opiniones dentro del modelo periodístico.

Por último, un cuarto grupo de estudiosos del tema de la desinformación, entre ellos Sampedro (2001), López (2004) o Romero (2011, 2012a y 2012b), consideran que la desinformación es estructural e inherente a la propia información, por lo que es imposible informarse sin a la vez quedar desinformados. En palabras de López (2004): "Hemos llegado a una situación en la que la información coincide con la desinformación, vivimos en una época de la no-información", razón por la que la aldea global con todas sus características tecnológicas deja a los ciudadanos más desinformados que nunca.

\subsection{La naturaleza desinformativa de los medios de comunicación}

La característica mercantil de los medios de comunicación privados, y política de los medios públicos, no está muy alejada de las realidades de cualquier medio de producción, en el que una empresa manufactura un producto que circulará por un canal de distribución hasta llegar a un consumidor. Al menos así ha sido analizado por Rodrigo Alsina (1995 y 2001) en un trinomio de producción, circulación y consumo con el que identifica la preexistencia de condiciones político-económicas que determinarán el enfoque de la industria comunicativa $\mathrm{y}$, por ende, su producto, sus estrategias discursivas y sus potencialidades tecnológicas. Habla también de una situación precomunicativa de la audiencia receptora que determinará la propia penetración e injerencia de las ideas expuestas por estos medios en la opinión pública (ibídem). Parafraseando el título del primer capítulo de Understanding Media: The Extensions of Man (1964), el estudio más influyente de Marshall McLuhan, un medio de comunicación bien puede ser un vehículo de pensamiento, pero también puede ser el conductor del mismo (McLuhan, 2003).

En el caso de los medios de comunicación, que dependen de personalidad jurídica de carácter público, la diferencia radica en que predominarán las condiciones políticas por sobre las económicas. Sin embargo, Rodrigo (1995, 2001) intenta demostrar con su teoría que existen unas circunstancias precomunicativas claras que definirán lógicamente el enfoque informativo de cada medio.

Como con anterioridad se ha reseñado, el tratamiento que se le da a las informaciones a través de los medios de comunicación (en especial la prensa, la radio y la televisión) en la influencia de su propia mediamorfosis y cambios en el propio ecosistema comunicativo, viene a coexistir con un modelo de periodismo banalizado, un círculo vicioso de oferta y demanda informativa, de prelación del entretenimiento sobre el objetivo de informar o, incluso más importante, de educar, de carencias de pluralismo, de aumento del interés interpretativo $\mathrm{u}$ opinativo sobre la propia necesidad investigativa, y lo hace recaer en un "periodismo de la no información" (Ortega, 2006: 17).

El problema planteado por Ortega (ibídem: 15-50), atendiendo evidentemente a las características actuales de los medios de comunicación masivos, es el incremento 
desproporcionado de la capacidad de "inventar, falsear o tergiversar" acontecimientos (ibídem: 18), que da origen a un modelo profesional que responde a la demanda de esta seudoinformación y que muchas veces sustituye a la propia información. De la misma manera, Galdón (2006: 27-42) critica al modelo del periodismo basado en el deseo de aumentar la cantidad y no la calidad de las informaciones que, apoyado por las tecnologías de la comunicación e información, logra en la actualidad empeorar progresivamente la aptitud del trabajo periodístico.

La industria de la comunicación, buscando entonces la máxima rentabilidad, apuesta por la producción masiva más que por la calidad de los contenidos y genera de esta forma "productos enlatados" para un consumo de abundante audiencia. Mas de Xaxás (2005: 42) expone la situación, refiriendo que "el secreto del progreso siempre ha sido producir más, mejor y más barato. Esta lógica aplicada en la realidad de un medio de comunicación, garantiza lo más rápido y más barato a costa de lo mejor, es decir, del rigor y, en última instancia, de la honestidad". Asimismo, asevera que "las noticias cada día se parecen más a la comida basura: son apetitosas, baratas, rápidas y fáciles de conseguir. Al tragarlas uno tiene, incluso, la sensación de estar haciendo algo muy positivo por su cuerpo y su mente".

Chomsky y Herman (1990: 69) afirman que el modelo de los medios de comunicación masiva actúa como activo propagandístico a través de varios filtros, entre los que destacan: a) el tamaño, la concentración de propiedad y orientación de las empresas dominantes; $b$ ) la publicidad como fuente de ingresos; $c$ ) la dependencia de los medios hacia el gobierno y/o las empresas; y d) la acción de los grupos de presión sobre los periodistas. A este respecto, es menester relacionar lo dispuesto con la realidad de los medios, que en su mayoría (sobre todo en países industrializados o en vías de desarrollo) pertenecen a grupos multimedia, sociedades mercantiles internacionales cuyo producto en venta es la información. De acuerdo con Muchielli y Thuiller, el hecho de que el Estado otorgue concesiones de explotación de ondas/espacios, que son bienes escasos y determinados, desemboca irremediablemente en concentración y centralización, por lo que se recae en una asimetría evidente para los medios independientes, locales o menos transnacionales (ápud De Bustos, 1993: 101).

Lo que viene a ocurrir entonces con la concentración multimedia es un efecto desinformativo, propio del ecosistema comunicativo actual, el denominado efecto ventrílocuo: "un solo dueño, múltiples voces" (Arráez, 1998). Esto podría dar lugar a la unificación de criterios informativos y de programación, aun cuando las líneas editoriales parecieren disímiles, por lo que la multiplicidad de canales u opciones no precisamente es un factor determinante del pluralismo informativo, ideológico o de la libertad de expresión, sino pudiera ser reflejo directo de una mayor concentración empresarial de la titularidad de esos medios.

\subsection{La sociedad como víctima propiciatoria de la desinformación}

La dimensión social cobra un papel primordial en la eficacia de la desinformación bajo la estructura que presupone que toda manipulación del mensaje público de difusión masiva es una aberración y un abuso de poder de aquellos que tienen (sea por autoridad, por poder o por credibilidad) acceso al podio discursivo social para ejercer una influencia ilegítima 
sobre la propia opinión pública. Así, el estudio de la desinformación debe iniciarse a través del examen conductual de las élites simbólicas que pudieren manipular el pensar colectivo en favor de sus propios intereses (Van Dijk, 2006).

Ser parte, entonces, de un principio en el que el ser humano necesita explicaciones para entender su propia realidad y las institucionalizaciones de realidades compartidas y socializadas (Searle, 1997: 49; Watzlawick, 1979: 32), lo que se une a una necesidad de las élites simbólicas de ejercer un control discursivo que, desde las primeras teorías de la comunicación y el despertar del interés académico, en la primera mitad del siglo XX, le ha otorgado a la comunicación la capacidad de atender bajo su disciplina las estructuras de la "sociedad de control" (Lasswell, Dwight y Lazarsfeld) desde la planificación de la propaganda bélica de las dos guerras mundiales hasta la redacción de géneros informativos actuales.

Esa estructura de información mesurada se aleja en parte de ser una expresión clara de la realidad y se convierte en selección prudente de una agenda pública bajo la triangulación de tres elementos fundamentales del estudio comunicativo: discurso, cognición y sociedad (Van Dijk, 2006: 22), en el que se necesita un enfoque analítico discursivo y semiótico porque la mayoría de los contenidos desinformativos se difunden mediante texto, palabra hablada o imagen y, a la vez, dependen de un proceso cognitivo de interacción podersúbditos (de acción discursiva) y de una sociedad cada vez más incapaz de acceder a datos privilegiados por sí mismos, lo que genera una ávida demanda de información para entender sus propias realidades compartidas a través de intermediarios.

El panorama de la dimensión social exige, entonces, que una minúscula parte de la población tenga acceso privilegiado a fuentes de difusión de información (como medios de comunicación, actos parlamentarios o textos académicos) por lo que el resto generalmente son receptores pasivos e inertes del mensaje. Esta interacción (caldo de cultivo propicio para la desinformación) resulta legítima por su naturaleza, ya que es la propia sociedad quien le otorga el poder de acceso al podio discursivo a esa élite simbólica. Esta es, a la vez, ilegítima por sus efectos, debido al ejercicio continuo de un poder lineal descendente que busca que los receptores actúen de una manera distinta de cómo lo harían con una información veraz (Romero, 2011: 8).

Esta arista social ha tomado cierto interés en el campo académico, no sólo en el que se basa en las teorías críticas o marxistas de la comunicación de Adorno, Horkeimer o Habermas, sino también en el que trata el creciente control y disminución de la competencia por el flujo globalizador que genera una especie de oligopolio trasnacional de medios de comunicación, cada vez más centralizados en gigantescos consorcios que crean una especie de "dumping informativo", en el que las realidades vienen expuestas de una determinada manera bajo cierto esquema de pensamiento único que atenta contra la pluralidad (Rubido y otros, 2009).

En este sentido, la opinión pública no es ajena a que los medios ofrecen miradas sesgadas de las realidades. El problema es que considera irremediable esa cadena de sucesos que, como si anduviera por el laberinto de Creta, la puede echar en las fauces del Minotauro y 
conducir al patíbulo de la desinformación. La intelección del mensaje (Brajnovic, 1991: 93-94) y la aprehensión y extracción de realidades del universo desinformativo por parte de la sociedad (Galdón, 2006: 235) son dos vías iniciales de control y contrapeso a la tergiversación informativa.

\subsection{Los estudios sobre la psicología de la desinformación}

El campo de la Psicología no ha permanecido ajeno al estudio de la desinformación a través de sus incidencias individuales y sociales. Desde la década de los setenta, ha surgido una sub-área de estudio acerca del "efecto desinformativo" (misinformation effect) liderada por Elizabeth Loftus, matemática y psicóloga conductista. La posición teórica conductista consiste en que el efecto desinformativo es aquella acción discursiva engañosa que interrumpe la decodificación de un acontecimiento y su posterior recuerdo en la memoria, ya que se altera su percepción al introducirse información errónea en el momento del razonamiento (Loftus y Hoffman, 1989: 100), por lo que vendría a constituir una interferencia previa a la formación de realidades.

Al respecto, el efecto desinformativo ocurre por dos circunstancias iniciales de nuestra memoria: la sugestión a través de la manipulación de conceptos y la atribución errónea de fuentes de información ambiguas por naturaleza (Saunders y MacLeod, 2002: 127) que variarán en función del marco de referencia y conceptual, de las ideologías, la edad, la memoria y los rasgos de personalidad (Lee, 2004: 997).

Por supuesto, la sugestión y la atribución errónea de fuentes de información no son las únicas responsables de la distorsión de la realidad. El proceso de recuperación y reconstrucción de recuerdos en nuestra memoria puede verse alterado sin influencia externa explícita (Loftus, 2005: 365), lo que podría devenir en efecto desinformativo propio e involuntario que puede afectar a terceros en interacciones comunicativas. Esto quiere decir que, para la teoría psicológica del efecto desinformativo, la desinformación no necesariamente necesita de un agente externo desinformante, sino que pudiere el propio individuo (en su proceso memorístico) afectar sus recuerdos $\mathrm{y}$, por ende, tener una aproximación distinta de la realidad percibida por sí mismo.

A la par de estas investigaciones, la psicología social, la sociología, la opinión pública, las ciencias políticas y la comunicación han contribuido a estudiar actitudes sociales como la “espiral del silencio" (Noelle-Neumann, 1995): un individuo adapta su comportamiento a las actitudes predominantes de su entorno por miedo al aislamiento, con la finalidad de sumarse a una idea colectiva, mayoritaria o consensuada, en la que los medios de comunicación definen matrices y climas de opinión sobre los que la sociedad actúa. Por esta razón, pudiere existir ciertamente una desinformación adaptativa al entorno para adecuar nuestros marcos de referencias al grupo al que deseemos formar parte.

El resultado de la propia presión social es un proceso en espiral que incita a otros individuos a sumarse a los cambios de opinión hasta que se establece como actitud prevalente, por 
lo que la lógica de fondo sostiene que, cuanto más difunden la versión dominante quienes tienen acceso privilegiado al podio discursivo social, más guardarán silencio las voces contrarias (Montero, 1993: 84).

\subsection{Algunos acercamientos pragmáticos al estudio de la desinformación}

El Grupo de Aprendizaje Colectivo de Comunicación Popular de la Escuela Popular de Personas Adultas "La Prosperidad - Madrid", pese a su carencia de método científico y de seguimiento de normas de citas y referencias, y con un enfoque totalmente empírico, se esforzó en estructurar un dossier denominado Técnicas de desinformación: Manual para la lectura crítica de la prensa, documento en el que, muy someramente, se señalan algunas de las técnicas más comunes en la praxis de los medios de comunicación que tienen el objetivo de desinformar.

Asimismo, García Avilés (ápud Herrero, 2009: 338-350) realiza una sucinta recopilación de técnicas de desinformación que cataloga en tres grupos: a) desinformación mediante el lenguaje; $b$ ) desinformación mediante la imagen; y c) desinformación mediante acciones. Son asociaciones de técnicas parecidas a las recopiladas por Michael Sweeny (1997) en "Twentyfive ways to supress the Truth: The Rules of Disinformation", que a pesar de también carecer de un marco metodológico, han sido usadas por diversos autores a manera de referencia.

Por su parte, Sylvain Timsit (2010), también sin una metodología clara ni seguimiento de normas de referencias pero con un gran enfoque pragmático, redactó un artículo ("Las diez estrategias de manipulación de masas") en el que identifica la distracción, la creación de problemas y soluciones, la gradualidad, el diferimiento, la infantilización de la audiencia, el contenido límbico-emocional, el mantener al público ignorante de la realidad, el reforzar la autoculpabilidad y el conocer a la audiencia como las claves que siguen los medios de comunicación para realizar la manipulación informativa. Hay que reseñar que este texto ha tomado cierto grado de viralidad en las redes sociales, bien que incorrectamente atribuido a Noam Chomsky.

\section{Reflexiones finales}

El término desinformación se acuñó oficialmente hace apenas 64 años, por lo que el tratamiento ontológico y científico ha sido contemporáneo, aún cuando existen indicios claros de que actividades desinformativas se pueden documentar en textos extremadamente antiguos, lo que nos puede estar hablando de una práctica tan antigua como la propia organización social.

En ese tratamiento de la comunidad científica, se evidencia una perspectiva de polisemia en el análisis morfosintáctico y sociológico de la desinformación, a la vez que muchos autores han optado por clasificar y diferenciar la desinformación dolosa (disinformation) de la desinformación culposa (misinformation) como dos aproximaciones distintivas del propio término, aún cuando el resultado sea el mismo, o sea, que la preterintencionalidad 
del emisor o fuente varía, por lo que se han evidenciado en el debate filosófico estos acercamientos conceptuales que sirven como marco de referencia para tener una mayor amplitud de un estado del arte en la instancia de la información.

Teóricos como van Dijk (2006), Klumpp (1997) o Galdón (1994 y 1996) han centrado sus esfuerzos en demostrar que, para que ocurra un efecto desinformativo, es necesario que el emisor tenga acceso preferencial al discurso público, tanto en el periodismo como en la academia o la política. Con todo, no hay consenso en si estaría inmersa en una variedad de la propia actividad informativa (como se ha reseñado, toda información podría venir con una carga desinformativa en sí misma), o si la desinformación se convierte en la acción contraria al informar, es decir, su antónimo, análisis que viene siendo objeto de un candente debate científico entre Floridi (1996, 2005 y 2011) y Fallis (2009 y 2011).

Parecería ir tomando forma una tercera teoría, alejada del debate reseñado, que considera a la desinformación una correlación estructural y, más aún, una característica propia del ecosistema comunicativo actual (López, 2004 y Romero, 2012). En él, todo medio de comunicación convive con unas circunstancias pre-comunicativas (Rodrigo, 1995) cuyo modelo de producción está más enfocado en producir cantidad y rentabilidad, sacrificando a veces calidad informativa (Galdón, 2006). Este proceso se une al propio "efecto ventrílocuo" de los grupos multimedia, que generan monopolios de agencias informativas $\mathrm{y}$, de este modo, un lugar privilegiado en el propio podio discursivo social.

En el campo de la psicología, se asume una posición conductista al comprender que la desinformación es un proceso que, o bien puede ser generado por un agente externo que (en el proceso de interpretación o reinterpretación de un acontecimiento) manipula a través del discurso y afecta al receptor por su propia sugestión y la asignación de fuentes erróneas; o bien puede generarse una auto-desinformación cuando, en el uso de la memoria episódica, somos incapaces de reinterpretar el acontecimiento de la misma forma que cuando lo observamos directa o indirectamente.

Si bien es cierto que se ha adelantado en el estudio de la desinformación en disciplinas como la lingüística, la semiótica, las ciencias de la información, el periodismo, la filosofía, la psicología y las ciencias políticas, no es menos cierto que no hay grandes avances científicos con respecto a las formulaciones retóricas de la desinformación, su pragmalingüística y psicolingüística. No hay un estudio de cada escenario y técnica de desinformación en relación con el contexto extralingüístico, su situación comunicativa (espacio / tiempo), el análisis del marco de referencia y contexto sociocultural de la audiencia, la importancia del tipo de relación inter-pares, el tono y las inferencias e interpretaciones que cada individuo, dentro de un colectivo, responde con respecto a un contenido desinformativo. En este sentido, el autor del presente artículo inicia con esta revisión documental su actividad investigadora en función de analizar las técnicas de desinformación desde la perspectiva de la pragmalingüística.

Luego de realizado el estudio bajo la metodología de revisión documental bibliográfica y hemerográfica de fuentes físicas y digitales por autores que han tratado el tema, se evidencia 
que muy pocos textos han abandonado el plano ontológico, filosófico y hermenéutico de la desinformación y sus debates conceptuales para adentrarse en su pragmática, revisando ejemplos del acontecer noticioso, político y económico utilizando el método investigativo e intentando alejarse, en la medida de lo posible, de intereses e ideologías para ofrecer no sólo la puntualización y características de cada estratagema de desinformación, sino la aplicabilidad y resultado en cada caso evidenciado.

Por su parte, se constata que los pocos tratamientos pragmáticos del estudio de la desinformación están vinculados a grupos asociados con sectores o líneas de pensamiento político específico, que obtienen principalmente sus ejemplos y clasificaciones a través del análisis empírico de textos periodísticos o acontecimientos políticos. De esta manera, el campo particular de la pragmalingüística de la desinformación y su incidencia en el propio comportamiento humano queda como práctica novedosa bajo el esquema del método científico. De esta manera, la atención de la comunidad científica ha estado más dispuesta a contribuir en el debate ontológico y epistemológico de la desinformación, logrando grandes avances en campos de su propia filosofía, aunque se le ha dado pocos tratamientos pragmáticos al tema, ofreciendo un campo de estudio novedoso y una oportunidad de emprendimiento académico en el análisis y clasificación de las estratagemas desinformativas más comunes en nuestra sociedad contemporánea.

Pero además de aventurarse en un nuevo paradigma de producción científica, este trabajo de investigación nace con el motivo de romper la estructura académica centrada en el debate ontológico y filosófico de la desinformación para darle una perspectiva pragmática al campo, buscando responder a una demanda social cada vez mayor de protección discursiva.

\section{Fuentes consultadas}

Adorno, T. y Horkeimer, M. (1994). La dialéctica de la ilustración. Madrid: Trotta.

Arráez, R. (1998). "La comunicación para el desarrollo. Su aplicación para el medio radio". Extraída el 25/VII/2013 desde http://www.ull.es/publicaciones/latina/a/40rosa.htm

Bednard, P. y Welch, C. (2008). Bias, Misinformation and the Paradox of Neutrality. Portsmouth: University of Portsmouth.

Bernays, E. _(1928). Propaganda. Nueva York: Horace Liveright.

_(1923). Crystallizing Public Opinion. Nueva York: Kessinger Publishing.

Brajnovic, L. (1991). El ámbito cientifico de la información. Navarra: EUNSA.

Buckland, M. (1991). "Information as thing”. Journal of American Society of Information Science, vol. 42, núm. 5, pp. 351-360. 
Butterfield, H. (1931). “The Whig Interpretation of History”. Extraída el 4/V/2013 desde http://www.eliohs.unifi.it/testi/900/butterfield/chap_2.html

Canevas, S. (2006). La Désinformation: Tous Responsables! Actes du 5éme colloque de Passy. Lorient: Editions Fauxtroll.

Catalán, M. (2009). “Introducción”, pp. 9-31. En Condorcet, M. ¿Es conveniente engañar al pueblo? Extraída el 4/V/2013 desde http://www.sequitur.es/wp-content/uploads/2010/09/ es-conveniente-enganar-al-pueblo.pdf

Chomsky, N. y Herman, E. (1990). Los guardianes de la libertad. Barcelona: Grijalbo.

De Bustos, M. (1993). Los grupos multimedia: Estructuras y estrategias en los medios europeos. Barcelona: Bosch.

De Echave-Sustaeta, J. (1992). La Eneida [Traducción]. Madrid: Gredos.

“Diccionario de la Lengua Rusa Ozhegov" (1949). Extraída el 9/X/2012 desde http://www. vedu.ru/ExpDic/6659

Doob, L. (1950) “Goebbels' Principles of Propaganda”. The Public Opinion Quarterly, vol. 14, núm. 3, pp. 419-442.

DPProgram (2010). "Disinformation Tactics: The Methods Used to Keep you in the Dark". Extraída el 5/V/2013 desde http://dprogram.net/2010/02/08/disinformation-tactics-themethods-used-to-keep-you-in-the-dark/

Dretske, F. (1981). Sensation and Perception. Cambridge: MIT Press.

Durandín, G. (1995). La desinformación, la información y la realidad. Madrid: Paidós.

Estados Unidos de América, Departamento de Estado.

_(1986). A report on the Substance and Process of Anti-US. Disinformation and Propaganda Campaings.

_(1981). Reporte Especial Número 88. Soviet Active Measures: Forgery, Missinformation, Political Operations.

Fallis, D.

_(2011). “Floridi on Disinformation”. Etica e Politica, vol. XIII, núm. 2, pp. 201-214.

_(2009). A Conceptual Analysis of Disinformation. Arizona: University of Arizona.

Fallet, L. (2001). La désinformation: mal incontorunable des médias? París: Mémoire de Communication.

Floridi, L.

_(2011). The Philosophy of Information. Oxford: Oxford University Press. 
_(2005). “Semantic Conceptions of Information”. Extraída el 5/XI/2012 desde http://plato. stanford.edu/entries/information-semantic/

_(1996). “The internet as a Disinformation Superhighway?” Extraída el 5/XI/2012 desde http://www.philosophyofinformation.net/publications/pdf/bnw.pdf

\section{Foucault, M.}

_(1989). Las palabras y las cosas: Una arqueología de las ciencias humanas. París: Gallimard.

_(1982). Vigilar y Castigar. Madrid: Siglo XXI.

Fox, C. (1983). Information and Misinformation: An investigation of the notions of information, misinformation, informing and misinforming. Westport: Greenwood.

Fraguas de Pablo, M. (1985). Teoría de la desinformación. Madrid: Alhambra.

Frické, M. (1997). "What are the advantages of hyperproof-Like reasoning systems?" British Journal for the Philosophy of Science, vol. 48, núm. 3, pp. 397-410.

Gackowski, Z. (2006). Quality of Informing: Bias and Disinformation Philosophical Background and Roots. Los Ángeles: Issues in Informing Science and Information Technology.

Galdón, G. (2006). Desinformación: Métodos, aspectos y soluciones. Pamplona: EUNSA.

García, J.

_(2009). "La desinformación”, pp. 327-346. En Herrero, J. (ed.). Manual de teoría de la información y de la comunicación. Madrid: Universitas.

_(2004). El Príncipe, de Maquiavelo. Madrid: Síntesis.

Gergen, K. (1992). El yo saturado: Dilemas de identidad en el mundo contemporáneo. Madrid: Paidós.

Grice, P. (1989). Studies in the way of words. Boston: Harvard University Press.

Grupo de Aprendizaje Colectivo (n. d.). "Técnicas de Desinformación, manual para la lectura crítica de la prensa". Extraída el 5/I/2013 desde http://pensamiento.kinoki.org/ contrainformacion/manual/desinformacion.htm

Habermas, J. (1981). Teoría de la Acción Comunicativa. Madrid: Taurus.

Hernón, P. (1995). "Disinformation and Misinformation through the Internet: Findings of an exploratory study”. Government Information Quarterly, vol. 12, pp. 133-139.

Herrero, J. (coord.) (2009). Manual de Teoría de la Información y de la Comunicación. Madrid: Universitas. 
Isralson, O. (1988). Vive la Désinformation, French Style. Boston: College of Communication.

Jacquard, R. (1988). La Desinformación: Una manipulación del poder. Madrid: Espasa.

Karlova, N. y Fisher, K. (2012). "Plz RT: A Social Diffusion Model of Disinformation and Misinformation for Understanding Human Information Behaviour". Proceedings of the ISIC2012, pp. 1-17. Extraída el 25/VII/2013 desde http://www.academia.edu/ 1981610/_Plz_RT_A_social_diffusion_model_of_misinformation_and_disinformation for_understanding_human_information_behaviour

Karlova, N. y Lee, J. (2011). "Notes from the Underground City of Disinformation: A conceptual investigation". Extraída el 25/VII/2013 desde http://www.academia.edu/ 1065634/Notes_from_the_Underground_City_of_Disinformation_A_Conceptual_ Investigation

Klumpp, J. (1997). Freedom and Responsibility in Constructing Public Life: Toward a Revised Ethic of Discurse [Symponsium on Academic Knowledge and Political Power at University of Maryland]. Netherlands: Kluwer Academic Publishers.

Lasswell, H. (1971). Propaganda technique in the World War. Boston: MIT Press.

Lee, K. (2004). “Age, Neuropsychological and Social Cognitive measures as predictors of individual differences in susceptibility to the Misinformation Effect". Applied Cognitive Psychology, vol. 18, núm. 8, pp. 997-1019. Extraída el 20/IV/2013 desde http:// onlinelibrary. wiley.com/doi/10.1002/acp.1075/abstract;jsessionid=8F2BEEFC299440D4 517BC424B1B6B433.d02t03

Lenin, V. (1902). “¿Qué Hacer? Problemas candentes de nuestro movimiento”. Extraída el 5/XI/2012 desde http://www.marxists.org/espanol/lenin/obras/1900s/quehacer/index.htm

Loftus, E. (2005). "Planting disinformation in the human mind: A 30-year investigation of the malleability of memory". Learning and Memory, vol. 12, núm. 4, pp. 361-366. Extraída el 20/IV/2013 desde http://learnmem.cshlp.org/content/12/4/361.full.pdf+html

Loftus, E. y Hoffman, H. (1989). "Misinformation and memory: The creation of memory". Journal Experimental Psychology, vol. 118, núm. 1, pp. 100-104. Extraída el 25/VII/2013 desde http://faculty.washington.edu/eloftus/Articles/hoff.htm

López, A. (2004). "La desinformación en la aldea global como forma de conocimiento". Ágora Revista de Ciencias Sociales, núm. 10, pp. 19-30.

Marcuse, H. (1964). El hombre unidimensional. México D. F.: Ariel. 
Martínez, J. (1987, diciembre 17 y 22). “Desinformar”. Revista Ya.

Mas de Xáxas, X. (2005). Mentiras: Viaje de un periodista a la desinformación. Barcelona: Destino.

McLuhan, M. (2003). Understanding the Media: The Extensions of Man. California: Gingko Press.

Montero, M. (1993). La información periodística y su influencia social. Barcelona: Universidad Autónoma de Barcelona.

Moragas, S. (1985). Sociología de la Comunicación. Barcelona: Gustavo Gili.

Muñoz, A. (1989). Política y nueva comunicación. El impacto de los medios en la vida política. Madrid: Fundesco.

Noelle-Neumann, E. (1995). La espiral del silencio. Opinión Pública: Nuestra piel social. Barcelona: Paidós.

O’Brien, T. (1989). Russian Roulette: Disinformation in the U.S Govenrment and News Media. South Carolina: University of South Carolina.

Ortega, F. (2006). Periodismo sin información. Madrid: Tecnos.

Pabón, J. (2006). La Odisea [Traducción]. Madrid: Gredos.

Ramírez, L. (2006). El arte de la guerra de Sunzi [Traducción]. Madrid: La Esfera de los Libros.

Real Academia Española (2001). Diccionario de la Real Academia Española (22 ${ }^{a}$ Edición). Madrid: Espasa.

Rivas Troitiño, J.

_(2001). Desinformación y Terrorismo: Análisis de las conversaciones entre el gobierno

y ETA en Argel (enero-abril 1989) en tres diarios de Madrid [Tesis doctoral]. Madrid: Universidad Complutense de Madrid, Facultad de Ciencias de la Información.

_(1995). "Desinformación: Revisión de su significado. Del engaño a la falta de rigor". Estudios sobre el mensaje periodístico, núm 2, pp. 75-83.

Rizo, M. (2009). La comunicación: ¿Ciencia u objeto de estudio? México D. F.: UNAM.

Roberts, A. (2005). "Spin control and freedom of information: Lessons for the United Kingdom from Canada". Extraída el 1/V/2013 desde http://onlinelibrary.wiley.com/ doi/10.1111/j.0033-3298.2005.00435.x/abstract;jsessionid=8D74D5223C6BD65CD5560 8F4428B96F3.d01t03 
Rodrigo, $\mathrm{M}$.

_(2001). Teoría de la comunicación: Ámbitos, métodos y perspectivas. Barcelona: Bellaterra.

_(1995). Los modelos de comunicación. Madrid: Tecnos.

Romero, L.

_(2012a). Aplicabilidad de técnicas de desinformación en la gestión comunicacional de crisis. Estudio de caso: BFA-Bankia [Trabajo final de Maestría]. Almería: Universidad de Almería, Facultad de Humanidades. Extraída el 25/VII/2013 desde http://www. academia.edu/2087620/ Aplicabilidad_de_Tecnicas_de_Desinformacion_en_la_Gestion_ Comunicacional_de_la_Crisis._Estudio_de_Caso_BFA-Bankia

_(2012b). "La desinformación en la Nueva Aldea Global". Revista Estudios Venezolanos de la Comunicación, núm. 159-160, pp. 52-55.

_(2011). "La manipulación informativa y la desinformación: La anomia de los receptores y el fomento de las víctimas propiciatorias". Extraída el 20/IV/2013 desde http://www.academia. edu/1200126/La_manipulacion_informativa_y_la_desinformacion_La_anomia_de_los_ receptores_y_el_fomento_de_victimas_propiciatorias

Rubido, S. y otros (2009). Medios de Comunicación y Manipulación: Propuestas para una comunicación democrática. Madrid: Universidad Nacional de Educación a Distancia.

Saariluoma, P. y Maksimainen, J. (2012). "Intentional Disinformation and Freedom of Expression”. International Review of Social Sciences and Humanities, vol. 3, núm. 2, pp. 9-20.

Sampedro, J. (2001). El mercado y la globalización. Barcelona: Destino.

Saunders, J. y MacLeod, M. (2002). "New evidence on the suggestibility of memory: the role of retrieval-induced forgetting in misinformation effects". Journal of Experimental Psychology, vol. 8, núm. 2, pp. 127-142.

Schiller, H.

_(1987). Los manipuladores de cerebros. Barcelona: Gedisa.

_(1973). Mind Managers. Boston: Beacon Press.

_(1969). Mass Communication and American Empire. Boston: Beacon Press.

Searle, J. (1997). The Construction of Social Reality. Nueva York: The Free Press.

Shultz, R. y Godson, R. (1984). Dezinformatsia: Active measures in Soviet Strategy. Washington: Pergamon.

Stahl, B. (2006). "On the difference or equality of information, disinformation and disinformation: A critical research perspective”. Informing Science Journal, vol. 9, pp. 83-96.

Stauber, J. y Rampton, S. (2001). "Trust us, We're experts: How industry manipulates science and gambles with your future". Los Ángeles: Tarcher-Penguin. 
Sweeny, M. (1997). "Twenty-Five ways to supress the truth: The rules of disinformation". Extraída el 03/II/2013 desde http://www.whale.to/m/disin.html

Timsit, S. (2010). "Les dix stratégies de manipulation de masses". Extraída el 15/II/2013 desde http://www.pressenza.com/fr/2010/09/les-dix-strategies-de-manipulation-de-masses/

Van Dijk, T. (2006). "Discurso y manipulación: discusión teórica y algunas aplicaciones". Revista Signos, vol. 39, núm. 60, pp. 49-74.

Watzlawick, P. (1979). ¿Es real la realidad? Confusión, desinformación, comunicación. Barcelona: Herder. 